\title{
TRANSCENDÊNCIA DA PALAVRA POÉTICA A PARTIR DO ESPAÇO PAISAGÍSTICO
}

\section{TRANSCENDENCE OF THE POETIC WORD FROM THE LANDSCAPE SPACE}

\section{TRASCENDENCIA DE LA PALABRA POÉTICA DEL ESPACIO PAISAJÍSTICO}

\author{
Natália Ferreira Santos ${ }^{1}$ \\ Universidade Estadual de Goiás, Goiás, Brasil \\ José Elias Pinheiro Neto ${ }^{2}$ \\ Universidade Estadual de Goiás, Itapuranga, Brasil
}

\begin{abstract}
Resumo: Essa pesquisa tem por objetivo analisar a paisagem enquanto um espaço capaz de possibilitar um dos recursos mais importantes da poesia que o é de transcender a palavra poética. A metodologia adotada nessa pesquisa foi a de revisão bibliográfica. Os resultados mostram que os espaços poéticos permitem aos indivíduos uma relação de intercambialidade entre a realidade e a imaginação, objetivo e subjetivo, esses elementos materiais e imaginários são indissociáveis e se interagem de maneira incessante, dando, então, vida à palavra poética.
\end{abstract}

Palavras-chave: Poesia. Subjetivo. Transcendência.

Abstract: This research aims to analyze the landscape as a space capable of enabling one of the most important resources of poetry, which is to transcend the poetic word. The methodology adopted in this research was the literature review. The results show that poetic spaces allow individuals an interchangeable relationship between reality and imagination, objective and subjective, these material and imaginary elements are inseparable and interact incessantly, thus giving life to the poetic word.

Keywords: Poetry. Subjective. Transcendence.

Resumen: Esta investigación tiene como objetivo analizar el paisaje como un espacio capaz de habilitar uno de los recursos más importantes de la poesía, que es trascender la palabra poética. La metodología adoptada en esta investigación fue la revisión de la literatura. Los resultados muestran que los espacios poéticos permiten a los individuos una relación intercambiable entre realidad e imaginación, objetiva y subjetiva, estos

\footnotetext{
1 Graduação em Letras: Língua Portugesa, Língua Inglesa e suas respectivas Literaturas pela Universidade Estadual de Goiás, onde participou de projetos de pesquisa e de extensão voltados para o ensino de literatura. Atualmente é mestranda em Língua, Literatura e Interculturalidade pela Universidade Estadual de Goiás, Câmpus Cora Coralina. E-mail: natalia.f.s@outlook.com

${ }^{2}$ Universidade Estadual de Goiás, Professor nocâmpus Itapuranga desenvolve atividades de ensino e pesquisa nas graduações de Letras e Geografia, exerce também o cargo de Coordenador Adjunto do Curso de Letras (Português/Inglês). E-mail: joseeliaspinheiro@gmail.com
} 
elementos materiales e imaginarios son inseparables e interactúan incesantemente, dando vida a la palabra poética.

Palabras clave: Poesía. Subjetivo. Trascendencia.

\section{INTRODUÇÃO}

O espaço devaneador, tendo em especificidade o espaço paisagístico, se faz matéria primordial para muitos dos poetas na busca da transcendência da palavra poética, uma vez que, a partir da contemplação desse espaço o poeta consegue unir, em unissonância, o objeto contemplado, paisagem, com o ponto de vista perceptivo e subjetivo, fazendo surgir o que Michel Collot (2013) considera como uma interação permanente entre o objetivo e o subjetivo.

Para Gaston Bachelard (1978) o espaço poético é visto como a materialidade capaz de possibilitar ao indivíduo o devaneio poético, contudo, só se é possível devanear em espaços que transmitem segurança e tranquilidade, e é dessa forma que a paisagem vai se caracterizar enquanto um local capaz de habitar o devaneio poético, tornando possível, então, a transcendência da palavra poética.

Compreendendo, então, a importância do espaço poético, essencialmente o espaço paisagístico, para a união entre o objetivo e o subjetivo, esse artigo tem como objetivo analisar como a paisagem se caracteriza enquanto um espaço capaz de possibilitar um dos recursos mais importantes da poesia que o é de transcender a palavra poética.

Propomos para a realização deste estudo a metodologia de revisão bibliográfica a partir de duas obras teóricas imprescindíveis para os estudos paisagístico, sendo elas $A$ poética do espaço de Gaston Bachelard (1978) e Poética e filosofia da paisagem de Michel Collot (2013), buscando diálogos entre ambas que comprovem que o espaço paisagístico nos possibilita a transcendência da palavra poética.

\section{GASTON BACHELARD E A POÉTICA DO ESPAÇO}

Gaston Bachelard (1884-1962) foi um filósofo e poeta francês que contribuiu largamente para os estudos literários. Ultrapassando as fronteiras de seu país, 
Natália Ferreira Santos

José Elias Pinheiro Neto
Geografia, Literatura e Arte, v.3, n.2, p. 114-129, jul./dez. 2021

DOI: 10.11606/issn.2594-9632.geoliterart.2021.184992

possibilitou teorias fundamentais em escala mundial, pesquisas essas voltadas não apenas para a teoria literária, como também para a psicologia, psicanálise e estudos clínicos acerca do comportamento humano. Debruçando-se, especialmente, sobre as questões psíquicas que envolvem os indivíduos, esse influente teórico lançou uma de suas principais obras, intitulada como A poética do espaço, publicada inicialmente em 1957.

A primeira discussão desencadeada por Gaston Bachelard é a imagem poética, que para o filósofo é imbuída de uma transubjetividade, ou seja, é capaz de tocar densamente a sensibilidade de distintas consciências. Essa transubjetividade da imagem poética pode também ser estudada a partir da fenomenologia (BACHELARD, 1978).

Em A poética do espaço, Gaston Bachelard (1978) se fundamenta nos pensamentos do filósofo e matemático alemão Edmund Husserl (1859-1938), responsável pelo estabelecimento dos estudos fenomenológicos. Em parâmetros filosóficos e para esta pesquisa, os estudos fenomenológicos consistem em questionar as teorias propostas por Sigmund Freud (1856-1939), que consideram a ciência como verdade absoluta para se analisar questões voltadas para o sonho, o inconsciente e a loucura. Em fenomenologia, divergentemente dos pensamentos freudianos, a primazia da razão é fortemente posta em indagação, propondo o estudo dos fenômenos e não apenas das essências (RIBEIRO; LOVATO; MERGEN, 2016).

Ainda nos parâmetros conceituais de fenomenologia, Edmund Husserl a considera como um modo radical de pensar, tendo o método investigativo de se apreender o fenômeno, ou seja, tudo o que penetra a consciência. A consciência, por sua vez, se caracteriza como um elemento fundamental para se estudar fenomenologia, pois é a partir dela que se compreende o mundo, sendo considerada pelo filósofo como algo plástico, isto é, sem rigidez e mutável, visto que a consciência se harmoniza com a temporalidade transigente (RIBEIRO; LOVATO; MERGEN, 2016).

Além do fenômeno ser tudo o que penetra a consciência, podemos observá-lo, também, como algo que é criado pela própria consciência, criação essa que vai além da apreensão externa, é por intermédio dessa força criadora dos fenômenos que a imagem poética pode ser inovadora, onde "Não a tomamos mais como "objeto". Sentimos que a atitude 'objetiva' do crítico sufoca a 'repercussão', recusa, por princípio, a 
profundidade, de onde deve tomar seu ponto de partida o fenômeno poético primitivo" (BACHELARD, 1978, p. 188).

Em a poética do espaço, Bachelard sente a necessidade de modificar suas percepções anteriores e partir para o método que nos propõe Husserl:

\begin{abstract}
Talvez perguntem por que, modificando nosso ponto de vista anterior, procuramos agora uma determinação fenomenológica das imagens. [...] Fiel a nossos hábitos de filósofo das ciências, tínhamos tentado considerar as imagens fora de qualquer tentativa de interpretação pessoal. Pouco a pouco, esse método, que tem a seu favor a prudência científica, pareceu-nos insuficiente para fundar uma metafísica da imaginação (BACHELARD, 1978, p. 184).
\end{abstract}

Tendo em vista que a fenomenologia se debruça a estudar os fenômenos sem as limitações científicas da razão, Gaston Bachelard (1978, p. 183) considera-a como primazia para se adentrar nos estudos da imaginação poética, uma vez que:

Um filósofo que formou todo o seu pensamento ligando-se aos temas fundamentais da filosofia das ciências, que seguiu, o mais precisamente possível, a linha do racionalismo ativo, a linha do racionalismo crescente da ciência contemporânea, deve esquecer seu saber, romper com todos os hábitos de pesquisas filosóficas, se quiser estudar os problemas colocados pela imaginação poética.

Destarte, o que Gaston Bachelard (1978, p. 184) preconiza é "voltar a uma fenomenologia da imaginação", analisando o fenômeno da imagem poética como um constructo subjetivo da consciência humana, uma vez que, para o teórico, a imagem poética não carece de um saber, pois ela emerge de uma consciência ingênua, sendo a poesia fruto da fenomenologia da alma.

Para Gaston Bachelard a imagem poética é uma ponte para que o poeta se deleite com ênfase nas aproximações à realidade, conjecturando, assim, mais força poética para além dos preceitos enraizados no sujeito, sejam preceitos linguísticos, culturais ou ideológicos, ou seja, o poeta, a partir da imagem poética, transcende, na mais densa subjetividade, o devaneio da alma (BENTO, 2010).

Ao retratar o devaneio em A poética do espaço, Gaston Bachelard (1978, p. 186187) considera que: 
Natália Ferreira Santos

José Elias Pinheiro Neto
Geografia, Literatura e Arte, v.3, n.2, p. 114-129, jul./dez. 2021

DOI: 10.11606/issn.2594-9632.geoliterart.2021.184992

Por si só, o devaneio é uma instância psíquica que frequentemente se confunde com o sonho. Mas quando se trata de um devaneio poético, de um devaneio que frui não só de si próprio, mas que prepara para outras almas deleites poéticos, sabe-se que não se está mais diante das sonolências. $\mathrm{O}$ espírito pode chegar a um estado de calma, mas no devaneio poético a alma está de guarda, sem tensão, descansada e ativa. Para fazer um poema completo, bem estruturado, será preciso que o espírito o prefigure em projetos. Mas, para uma simples imagem poética, não há projeto, e não lhe é preciso mais que um movimento da alma. Numa imagem poética a alma acusa sua presença.

Nesta perspectiva dos pensamentos bachelardianos, só é possível aproximar-se da imagem poética a partir do devaneio, quando o indivíduo vai ao encontro do âmago de sua intimidade. A intimidade, por sua vez, é experimentada pelo sujeito em espaços em que esse ele se vê livre para devanear (BACHELARD, 1978). O espaço poético, descrito pelo filósofo, é o espaço fértil para que a palavra literária tome forma e potencialidade a partir do devaneio.

Esse espaço poético é simbolizado aos leitores a partir da imagem de uma casa. Compreende-se que o ser humano, desde sua forma embrionária, é pertencente de uma casa, sendo ela o ventre da mãe, constituída principalmente pela água morna e acolhedora. Durante essa primeira morada, o espaço poético no mundo para esse indivíduo está, em sua maioria, sendo preparado para sua inserção na casa onde esse cultivará suas memórias e se formará enquanto sujeito pensante e crítico de seu mundo (DINARTE; CORAZZA, 2016).

A casa para Gaston Bachelard (1978) é vista não apenas como um signo de habitação, mas também como o local onde se constituirá um ambiente de intimidade consigo mesmo, visto que a casa é a expressão mais genuína da construção do eu. É nesse espaço poético que se possibilita a inter-relação entre os pensamentos, a memória e os sonhos, pois nele se preservam as melhores lembranças, como também experiências tristes.

Sendo assim, o espaço da casa se faz primordial para o espaço poético porque ela permite que o sonhador sonhe serenamente, a casa abriga o devaneio, e ela é o primeiro universo do indivíduo. É nesse espaço que se é possível idealizar o futuro e vagar em desejos quiméricos, e é esse espaço que permite que o sonhador guarde um extensivo número de lembranças (BACHELARD, 1978). 
Natália Ferreira Santos

José Elias Pinheiro Neto
Geografia, Literatura e Arte, v.3, n.2, p. 114-129, jul./dez. 2021

DOI: 10.11606/issn.2594-9632.geoliterart.2021.184992

Gaston Bachelard (1978) induz o leitor a refletir sobre a casa como um espaço de imaginação, essa casa, assim como a própria subjetividade, pode se caracterizar das mais diversas formas, visto que todo indivíduo apresenta sua própria casa e sua própria maneira de sonhar com esse espaço poético. De forma mais abrangente, possibilita uma constatação de que o indivíduo é como a casa, assim como ela, cheio de espaços e cantos em que se edifica o próprio cursar da vida.

O filósofo analisa as principais dimensões da casa, enfatizando que em cada ambiente pode-se possibilitar sentimentos diferentes. Um exemplo dado por ele é a divergência entre o porão e o sótão. O porão é caracterizado como um espaço em que se guardam objetos que não têm mais valor, ou seja, é um ambiente onde se preenche o vazio com inutilidades, esse espaço é, quase sempre, soterrado, sendo assim, o porão é um pequeno espaço na totalidade da casa, escuro e triste, como uma parte dos indivíduos, isto é, a parte em que se armazenam memórias tristes. Já o sótão, espaço localizado na parte superior da casa, sendo próximo ao sol e indo em direção ao céu, é o ambiente em que se guardam boas recordações, a parte alegre da casa/indivíduo, onde o sonhador edifica seus sonhos (BACHELARD, 1978).

Essa polaridade entre o porão e o sótão é posta como uma ressignificação dos sentidos da casa como cerne do imaginário poético. Ainda nessa dialética, o teórico, citando o psiquiatra suíço Carl Gustav Jung (1933), relata como o ser humano age ao escutar um barulho estranho em sua casa, esse por sua vez vai em direção ao sótão para se certificar, nos parâmetros racionais, que não há ninguém por lá, mas não se atreve a ir ao porão, posto que esse ambiente, fenomenologicamente, desperta pensamentos irracionais (BACHELARD, 1978).

Outro ambiente da casa descrito por Gaston Bachelard (1978, p. 286) como elemento do devaneio é o canto, "todo canto de uma casa, todo ângulo de um aposento, todo espaço reduzido onde gostamos de nos esconder, de confabular conosco mesmos, é, para a imaginação, uma solidão, ou seja, o germe de um aposento, o germe de uma casa". O canto é o espaço poético onde o ser humano regressa quando se é excluído, quando se está triste ou solitário, é nesse espaço poético que se é possível devanear no silêncio dos próprios pensamentos.

Analisando os pequenos espaços da casa, surge um questionamento acerca da metáfora da gaveta, para Henri Bergson, metaforicamente, a gaveta simboliza o 
Natália Ferreira Santos

José Elias Pinheiro Neto
Geografia, Literatura e Arte, v.3, n.2, p. 114-129, jul./dez. 2021

DOI: 10.11606/issn.2594-9632.geoliterart.2021.184992

conhecimento. Contudo, Gaston Bachelard compreende as palavras pelo viés poético e esboça críticas ao conceito e à metáfora, para o teórico o conceito é polido de rigidez, já a metáfora não é uma imagem pura que advém da alma, é, na verdade, uma imagem já fabricada, que não possui traços genuínos, diferentemente da imagem, que pode se caracterizar como um fenômeno primitivo e livre das apreensões externas (HORODYSKI; et al, 2011). É importante ressaltar que a descrição feita sobre a metáfora diz respeito à imagem poética e não sobre a forma de transcender essa imagem genuína na escrita poética, a qual a metáfora exerce função imprescindível, dessa forma, discutir-se-á a função da metáfora no próximo tópico deste artigo.

O indivíduo possui um ideário acerca da imagem da casa, sendo ela a que exprime conforto e proteção, fazendo o teórico chegar a outro espaço que é discutido em sua obra, o espaço do ninho. A simbologia do ninho é tomada acerca de uma imagem poética que possui ampla relevância no devaneio, o ninho para os indivíduos, assim como para os animais, representa a primeira morada, isto é, a infância, podendo expressar as lembranças e a pureza, um refúgio aos seres humanos, buscando sempre regressar ao ninho (casa dos pais e/ou espaço de origem) quando necessário, o ninho é, portanto, a imagem poética que simboliza o princípio, descrito por Gaston Bachelard (1978, p. 257) como "imagem primeira".

Ao analisar alguns dos espaços delimitados pelo filósofo, é possível afirmar que a obra é um compêndio sobre o ser humano, mostrando a formação psicoemocional do indivíduo no mundo de sua própria intimidade, quando esse sujeito pode se ver livre para o devanear (SILVA, 2015). Diante disso, o que se mostra em A poética do espaço, é que os ambientes detalhados por Gaston Bachelard não são considerados como meros objetos, mas sim como esses espaços poéticos que demarcam as relações simbólicas extraídas da dialética entre a realidade e a imaginação (CALERI; PEREIRA, 2018).

Os espaços descritos por Bachelard a partir da imagem da casa se configuram como espaços poéticos a partir daquilo que podemos denominar como visão romântica do espaço contemplado. Vemos, a toda palavra bachelardiana na Poética do espaço, essa ligação romântica entre o indivíduo e os espaços descritos, essa visão romântica decorre a partir de laços afetivos que o sujeito tece em meio ao espaço/paisagem que se encontra. 
Natália Ferreira Santos

José Elias Pinheiro Neto
Geografia, Literatura e Arte, v.3, n.2, p. 114-129, jul./dez. 2021

DOI: 10.11606/issn.2594-9632.geoliterart.2021.184992

É nessa perspectiva que podemos voltar ao espaço do ninho, visto que é nesse ambiente que se tece as maiores relações afetivas entre sujeito e espaço, configurandose, portanto, como a primeira paisagem romântica dos indivíduos.

Os pensamentos bachelardianos, portanto, compilam a complexa relação entre o indivíduo e o espaço poético, onde, por intermédio dos espaços discutidos na obra, pode se descobrir a fenomenologia dessa relação a partir da poesia que existe no espaço poético e no indivíduo, mas que somente as almas sensíveis e abertas ao devaneio podem experimentá-la (HORODYSKI; et al, 2011).

Tendo em vista a importância das contribuições de Gaston Bachelard acerca do espaço poético, surge a necessidade de se aprofundar na temática de poesia e espaço e compreender, de modo mais específico, a paisagem.

\section{MICHEL COLLOT E A POÉTICA DA PAISAGEM}

Michel Collot é um importante pesquisador sobre a paisagem na poesia moderna. Professor de Literatura na Universidade de Cambridge, vem contribuindo para a compreensão dos estudos de paisagem. Seu livro Poética e filosofia da paisagem (2013) é um conjunto de ensaios sobre o tema, o qual o grupo de pesquisa "Estudos de paisagem nas Literaturas de Língua Portuguesa" da Universidade Federal Fluminense juntamente com a Universidade Federal do Maranhão tiveram o trabalho minucioso de traduzir para a língua portuguesa

Michel Collot (2013) observa a paisagem não apenas como um ambiente geográfico, tampouco como um mero objeto de estudo, para ele a paisagem é uma possibilidade de ressignificações do mundo e da racionalidade. A paisagem ao mesmo tempo em que promove o pensamento o transcende como própria paisagem, fazendo surgir o que o autor chama de "pensamento-paisagem".

A paisagem subsidia o escritor a expressar sua poesia, além de constituir um imaginário que vai além dos valores simbólicos, culturais, econômicos e políticos, sua 
Natália Ferreira Santos

José Elias Pinheiro Neto
Geografia, Literatura e Arte, v.3, n.2, p. 114-129, jul./dez. 2021

DOI: 10.11606/issn.2594-9632.geoliterart.2021.184992

supremacia promove significações tanto subjetivas quanto transubjetivas, sendo engrenagem essencial para a transcendência da palavra poética.

Para Michel Collot (2013, p. 17), a paisagem deve ser entendida além das definições cognitivas, que a veem como um mero espaço ou como uma representação pictórica. A paisagem, nesse sentido, deve ser compreendida como "três componentes, unidos numa relação complexa: um local, um olhar e uma imagem". Nesta perspectiva, a paisagem é considerada pelo ensaísta como um fenômeno que exerce a função de unir o ponto de vista do sujeito ao espaço diante de si.

Assim como Bachelard (1978), Michel Collot (2013) também parte dos pressupostos fenomenológicos para entender o espaço da paisagem como elemento poético, contudo a fenomenologia, para este, não pode ser dissociada dos estudos científicos, pois é justamente essa união estrita que é capaz de ligar o objetivo com o subjetivo sem se perder os parâmetros lógicos.

Essa união entre objetivo e subjetivo, objeto/espaço e pensamento, sensível e inteligível é descrito por Michael Hamburger (2007) como a agregação do eu empírico (aquele que vive a realidade e é afetado por ela) com o eu poético (aquele que cria uma realidade subjetiva), cuja ligação contínua se torna responsável pelo sucesso de diversas obras poéticas publicadas em todos os períodos já existentes.

Seguindo essa linha de raciocínio, Michel Collot vê a paisagem como cerne dessa junção descrita por Michael Hamburger, uma vez que é a paisagem que possibilita a experiência da "interação permanente entre o dentro e o fora, o eu e o outro" (COLLOT, 2013, p. 26).

Essa interação permanente entre o dentro e o fora se faz possível pelo uso de metáforas. Michael Collot (2013), assim como Michael Hamburger (2007), ressalta que alguns escritores e filósofos enxergam o uso de metáforas como um elemento deplorável e que leva a poesia para uma decadência. Contudo Michael Hamburger (2007) entende que a metáfora se qualifica como primazia indispensável, visto que para o teórico é função da linguagem poética imbuir complexidade em sua compreensão, fazendo assim, com que o leitor faça uma leitura mais densa e se indague acerca das múltiplas possibilidades de compreensão poética. Já Michael Collot (2013) observa que o uso conceitual da língua ignora a forma sensível do signo linguístico, pois se prende em paradigmas pré-estabelecidos, fazendo como função primordial da linguagem 
poética explorar e cultivar essa sensibilidade a partir de metáforas, visto que é ela que envolve o pensamento, o espaço e a linguagem.

É nessa vertente que Michael Collot (2013, p. 50) enfatiza que a paisagem não se limita à sua caracterização conceitual de que se trata de uma "extensão de região" e que, ao contrário do que se supõem, a paisagem não é exclusivamente natural ou ligada a um país ou região. A paisagem de um escritor, como exemplifica o ensaísta, pode ser sua própria escrita, o que a inspira é o sentimento, que por sua vez não se faz de forma forçada.

A paisagem surge, assim, como um recurso imprescindível para os aspectos mais subjetivos do sujeito, tais quais "sensações, percepções, impressões e mesmo afeições, emoções e imaginações" (COLLOT, 2013, p. 51), aspectos esses que a percepção moderna acerca do universo não consegue mais exprimir.

É nesse sentido que se ressalta a importância da metáfora na relação entre a paisagem e a literatura, pois é esse recurso linguístico que possibilita a abertura de um dos elementos mais essenciais da poética: a imaginação. Sendo esse elemento responsável por elencar todos os aspectos subjetivos descritos pelo autor. Diante disso, Michael Collot (2013, p. 52) destaca que entre todos os gêneros literários, é a poesia lírica que melhor expressa a experiência subjetiva com a paisagem, pois, diferentemente do romance, nela "o mundo é percebido de dentro [...] enquanto que o narrador de um romance adota um ponto de vista sempre mais ou menos exterior".

Seguindo essa concepção, Michael Collot (2013) adota um adjetivo crucial para se adentrar aos estudos de paisagem, sendo ele "romântico", o teórico afirma que as paisagens se fundamentaram como românticas, mesmo antes da ascensão do período do Romantismo, uma vez que esse adjetivo evidencia a sensibilidade, que, como já analisado, exerce ampla influência na compreensão dos estudos paisagísticos.

A gênese do adjetivo romântico surgiu como uma necessidade de destituir a paisagem dos parâmetros picturais que a engendravam no campo artístico, fazendo incidir, mais precisamente, "as impressões, as emoções, os devaneios suscitados por paisagens capazes de abalar fortemente a sensibilidade e a imaginação" (COLLOT, 2013, p. 63). Compreende-se, portanto, que a instauração desse adjetivo surge como a urgência de se transcender a paisagem a uma nova sensibilidade, isto é, fazer com que a paisagem rompa com os limites clássicos que a denominavam apenas como um plano de 
fundo para as pinturas e, fazendo-a assumir um papel imprescindível para o sujeito e a sua inserção no mundo/espaço.

Destarte, o adjetivo romântico expressa como a paisagem se entrelaça ao mundo a partir de uma ligação afetiva que é conferida ao sujeito ao contemplar a paisagem, contudo Michael Collot (2013) ressalta que as paisagens que mais penetram o ímpeto romântico são as descritas como "selvagens", ou seja, aquelas que o ser humano ainda não dominou e modificou, sendo as paisagens circunscritas em uma natureza virgem, uma vez que "Romântica é a paisagem cuja pureza solicita a imaginação, segundo um movimento análogo ao da própria criação" (COLLOT, 2013, p. 65).

Outra questão a ser analisada a partir dessa linha teórica traçada por Michael Collot (2013) é o fato de que além das paisagens selvagens serem mais adeptas ao adjetivo romântico, também é necessário que o indivíduo não apresente marcas da cultura desgastada da modernidade, que muito interferiu e ainda interfere na origem de diversas paisagens. $\mathrm{O}$ autor ressalta que, para que se exprima os devaneios suscitados da paisagem no coração de homens e mulheres, é imprescindível que esses se mantenham “próximos da natureza original” (COLLOT, 2013, p. 71).

A paisagem romântica exerce uma intercambialidade entre o sujeito e o mundo, sendo uma troca contínua que Michael Collot (2013, p. 224) denomina de "o sujeito fora de si", imbuindo tanto a interiorização da paisagem no eu, quanto a exteriorização desse eu na paisagem, fazendo com que termos distintos como, objetivo/subjetivo, interior/exterior, sensível/inteligível, sujeito/espaço, sejam indissociáveis e que se relacionem mutuamente em prol da transcendência da palavra poética. Tal relação somente se faz possível pela força recíproca entre o sujeito e seu espaçamento na paisagem, logo "a paisagem exprime o sujeito, mas ultrapassa-o e abre-o, assim, a uma dimensão desconhecida dele mesmo e do mundo" (COLLOT, 2013, p. 83).

Filosoficamente, essa convergência entre o sujeito e a paisagem romântica possibilita a revelação e a formulação do eu, como também torna possível que o sujeito, ao experimentar a paisagem romântica, saia de si a partir do devaneio. É nesse panorama que o vínculo entre a paisagem romântica e o sujeito não se limita simplesmente em uma correlação visual, é preciso uma troca contínua entre o sujeito e a paisagem romântica, destarte esse devaneio eclode de um fluxo de imaginação e de uma movimentação da alma perante a paisagem romântica. 
Natália Ferreira Santos

José Elias Pinheiro Neto
Geografia, Literatura e Arte, v.3, n.2, p. 114-129, jul./dez. 2021

DOI: 10.11606/issn.2594-9632.geoliterart.2021.184992

O devaneio, portanto, exerce papel imprescindível para os poetas, essencialmente aos do lirismo, pois é devaneando em função da paisagem que conseguir-se-á representar o objeto e o sujeito em uníssono, uma vez que, como já enfatizado "a paisagem é uma troca em duplo sentido entre o eu que se objetiva e o mundo que se interioriza" (COLLOT, 2013, p. 89).

Essa troca se amplia, afetivamente, no sujeito lírico, sendo uma relação paradoxal, pois ao mesmo tempo em que imbui emoções densas, também propicia uma certa tranquilidade, uma vez que a contemplação da paisagem oferece ao sujeito o alento de se desligar de seus próprios limites e objeções.

A paisagem romântica, assim, exerce mais veemência na poesia lírica, pois nos versos líricos revestem-se a musicalidade e a sensibilidade que "dá ao poema sua tonalidade, no duplo sentido do termo" (COLLOT, 2013, p. 90). Essa musicalidade e sensibilidade se projetam na poesia lírica através da fusão entre o sujeito, o espaço poético e as palavras, que se unem em unissonância no momento em que o sujeito lírico transcende o dentro e o fora, a linguagem e a paisagem. Posto isso, Collot (2013, p. 91) observa que o poeta nada mais é do que o mediador dessa transcendência, sendo um "instrumento dócil nas mãos do universo".

A paisagem se torna mais significativa na poesia lírica pelo fato de possibilitar, através de palavras, toda a sensibilidade do sujeito em sua relação mútua com o mundo. Porém, essa estética, tão fundamental para o desenvolvimento poético, se torna ameaçada no momento em que artistas e escritores sugerem uma estética que rescenda o real, tal qual é, ou seja, que não experiencie questões subjetivas do eu.

A eclosão desse realismo faz surgir o que Michael Hamburger (2007) denota como uma quase destruição da poesia, pois como já observado, a poesia deve reunir o objeto com a sensibilidade do eu que o contempla. Essa instabilidade na poesia influencia, amplamente, um dos poetas mais célebres do mundo, Charles Baudelaire (1821-1867), o qual foi reconhecido como o precursor da arte moderna por retratar alegoricamente a paisagem da cidade urbana como cerne de sua poesia.

Charles Baudelaire, poeta romântico-moderno, é também o autor responsável por ressignificar o adjetivo romântico da poesia paisagística, pois ele o liberta de seus principais excessos, trata-se, portanto, não de se distanciar da realidade, mas de deixar os traços subjetivos incólumes, respeitando a essência, tanto do real, quanto do 
Natália Ferreira Santos

José Elias Pinheiro Neto
Geografia, Literatura e Arte, v.3, n.2, p. 114-129, jul./dez. 2021

DOI: 10.11606/issn.2594-9632.geoliterart.2021.184992

subjetivo, uma vez que a poesia deve se resultar da relação ilimitada entre o espaço/paisagem e o eu.

A interferência recíproca entre o real e o subjetivo/imaginário, a que tanto se enfatiza sua essencialidade para a poesia, é capaz de fornecer uma sensibilidade inesgotável ao objeto contemplado pelo subjetivo, possibilitando descobertas e ressignificações da paisagem, pois "a paisagem só pode ser descoberta a partir de um ponto de vista necessariamente subjetivo" (COLLOT, 2013, p. 103).

Michael Collot (2013) considera, portanto, que a paisagem é imbuída tanto de uma realidade objetiva/exterior quanto subjetiva/interior, sendo tais traços indivisíveis, formando, assim, o logos da poética da paisagem. Esse pensamento é descrito também por Octávio Paz (1982), declarando que a poesia sempre procurou meios para rescindir a distância entre a palavra e o objeto/espaço representado, sendo característica primordial do poema a busca pela transcendência da palavra para além dos signos linguísticos, evidencia-se aqui que não se trata de se desligar da realidade, mas sim de uni-la ao subjetivismo do sujeito.

É por essa linha que Michael Collot (2013) compreende que a pintura e a literatura não podem partir dos pressupostos traçados por Hugo Friedrich (1904-1978), que defendia com veemência a instauração de um realismo dissociado da subjetividade, uma vez que para Michael Collot, assim como para Michael Hamburger (2007), a função do poeta não é a de afirmar uma verdade absoluta, mas sim de explorá-la constantemente, exploração esta que somente será possível a partir da homogeneização entre o dentro e o fora, objetivo e subjetivo, espaço e sujeito.

É essa ligação entre elementos tão distantes que possibilitou a ascensão de Charles Baudelaire, pois esse poeta, ao retratar os traços parisienses citadinos como paisagem, uniu o objeto (cidade urbana) com o ponto de vista onírico do sujeito (subjetivação), porém respeitando tanto a realidade exterior quanto interior, diante disso Michael Collot (2013, p. 133) ressalta que "É este investimento sensível e afetivo que transforma o espaço urbano em paisagem e que dá às descrições sua tonalidade lírica".

Evidencia-se, portanto, que a poesia, assim como afirma Michael Hamburger (2007, p. 35) "encarna ou representa a verdade", mas tal representação sem a subjetividade não é, necessariamente, poesia, uma vez que, como já mencionado, a poesia resulta da junção entre a objetividade/espaço e a subjetividade/sujeito. Nesse 
Natália Ferreira Santos

José Elias Pinheiro Neto
Geografia, Literatura e Arte, v.3, n.2, p. 114-129, jul./dez. 2021

DOI: 10.11606/issn.2594-9632.geoliterart.2021.184992

panorama, Michael Hamburger (2007) ressalta que a poesia nunca excluirá o humano, pois quando um poema retrata apenas um objeto, ela não está, precisamente, descrevendo-o, mas sim expressando o ponto de vista subjetivo do sujeito em relação a esse objeto.

Ao se deparar com as afirmações acerca da importância da poética da paisagem na poesia, se faz trivial o questionamento sobre como fica essa relação tão complexa e indivisível entre o sujeito e a paisagem no final da primeira metade do século XX e no início de sua segunda metade em relação aos efeitos do pós-guerra, onde muitas das paisagens se desconfiguraram pelo assolamento causado por esse período. Mas é justamente a paisagem que possibilitará, tanto ao poeta quanto aos leitores, o alento em meio à desolação causada pela Segunda Guerra Mundial. A paisagem colabora, incisivamente, para a edificação de uma das funções mais essenciais da poesia, a qual Michael Hamburger (2007) denota como a de recuperar pessoas. A paisagem, portanto, "constitui para o indivíduo moderno uma oportunidade única de recomeçar" (COLLOT, 2013, p. 156).

A poética da paisagem, assim, se configura como uma fonte inesgotável da poesia, pois possibilita, além da interseção entre o dentro e o fora, uma contínua reinvenção da expressão e de uma constante transformação de formas, pois tal poética se edifica em prol de uma plasticidade que sempre acompanhará as transições do indivíduo. Sendo, eficazmente, o cerne, mesmo que de modo desconfigurado e longe do sublime, de poetas como Charles Baudelaire (1944), em As flores do mal, e Carlos Drummond de Andrade (1945), em A rosa do povo, obras essas que foram capazes de unir o sensível e o inteligível, o dentro e o fora, no mais puro lirismo ao ponto de esse tocar e revigorar almas densamente feridas, e aquele de trazer novos conceitos do belo (BRANDÃO, 2019).

\section{CONSIDERAÇÕES FINAIS}

A partir das discussões aqui realizadas sobre o espaço poético e paisagem, podemos perceber que a paisagem é vista para muitos dos indivíduos como a simbologia do ninho, descrita por Gaston Bachelard (1978), uma vez que ela, assim como o espaço do ninho, nos permite refúgio, segurança e liberdade para devanear, 
Natália Ferreira Santos

José Elias Pinheiro Neto
Geografia, Literatura e Arte, v.3, n.2, p. 114-129, jul./dez. 2021

DOI: 10.11606/issn.2594-9632.geoliterart.2021.184992

evidenciando uma das principais características do espaço paisagístico descrita por Michael Collot (2013), que é a de transcender a palavra poética a partir da união entre o objetivo e o subjetivo.

Tal união, como vimos ao longo desta pesquisa, decorre da visão romântica do indivíduo diante do espaço/paisagem do qual está inserido, possibilitando-nos entender, dessa forma, que a poesia se resulta por intermédio da relação indissociável entre os elementos materiais e imaginários, e nada mais é do que o ponto de vista subjetivo do indivíduo acerca do espaço poético que o circunda.

Diante disso, podemos concluir que a paisagem se estabelece enquanto um espaço privilegiado para o mundo poético justamente pela sua capacidade de unir o ponto de vista subjetivo com o objeto que está sendo contemplado, pois é por intermédio dessa união que se faz possível a transcendência da palavra poética, fazendonos atingir elementos essenciais para a leitura da arte literária.

\section{REFERÊNCIAS}

ANDRADE, Carlos Drummond. A rosa do povo. São Paulo: Círculo do Livro, 1945.

BACHELARD, Gaston. A poética do espaço. São Paulo: Abril Cultura, 1978.

BAUDELAIRE, Charles. As flores do mal. Rio de Janeiro: Livraria José Olympio, 1944.

BENTO, Elói Alberto. Gaston Bachelard: o lado nocturno do filósofo. 2010. 138 f. Dissertação (Mestrado em Filosofia da Educação) - Faculdade de Letras da Universidade do Porto, Porto, 2010.

CALERI, Márcio José; PEREIRA, Marcio Roberto. (Resenha) A Poética do Espaço. In: InterEspaço: Revista de Geografia e Interdisciplinaridade, v. 4, n. 13, 2018. p. 275-278.

COLLOT, Michel. Poética e filosofia da paisagem. Rio de Janeiro: Editora Oficina Raquel, 2013.

DINARTE, Luiz Daniel Rodrigues; CORAZZA, Sandra Mara. Espaço poético como tradição didática: Bachelard e a imagem da casa. In: Educação \& Formação, v. 1, n. 2, 2016. p. 135-148.

HAMBURGER, Michael. A verdade da poesia: tensões na poesia modernista desde Baudelaire. São Paulo: Cosac Naify, 2007. 
Natália Ferreira Santos

José Elias Pinheiro Neto
Geografia, Literatura e Arte, v.3, n.2, p. 114-129, jul./dez. 2021

DOI: 10.11606/issn.2594-9632.geoliterart.2021.184992

HORODYSKI, Graziela Scalise; NITSCHE, Leticia Bartoszeck; OLIVEIRA, Dircélia Maria Soares de; BIESEK, Ana Solange. Gaton Bachelard e o espaço poético: Contribuições para a geografia e o turismo. In: $R A^{\prime} E G A$, v. 22, n. 1, 2011. p. 74-94.

PAZ, Octávio. O Arco e a Lira. Rio de Janeiro: Nova Fronteira, 1982.

RIBEIRO, Amanda de Cássia Borges; LOVATO, Ana Cristina do Amaral; MERGEN, Carla Cristiane. A imaginação criadora nos devaneios de Gaston Bachelard: Possibilidades em educação. In: ANAIS - II Fórum Internacional de Educação, 2011, Universidade de Santa Cruz do Sul, 2016.

SILVA, Felipe Cabañas da. Geografia e poesia lírica: considerações sobre a poética do espaço, de Gaston Bachelard. In: GEOUSP - Espaço e Tempo, v. 19, n. 1, 2015. p. 6075 .

Recebido em 28/04/2021.

Aceito em 29/07/2021.

Publicado em 15/12/2021. 